\title{
Helicobacter pylori treatment in Turkey: Current status and rational treatment options
}

\author{
(D) Mustafa Kaplan, ${ }^{1}$ (D) Alpaslan Tanoglu, ${ }^{1}$ (D) Tolga Duzenli, ${ }^{1}$ (D) Ayse Nurdan Tozun ${ }^{2}$ \\ ${ }^{1}$ Department of Gastroenterology, Sultan Abdulhamid Han Training and Research Hospital, Istanbul, Turkey \\ ${ }^{2}$ Department of Gastroenterology, Acibadem University, Istanbul, Turkey
}

\begin{abstract}
According to the TURHEP study, the prevalence of Helicobacter pylori in Turkey is $82.5 \%$. After FDA approval in 1995 , many countries have used standard triple therapy (proton pump inhibitor $40 \mathrm{mg}$ b.i.d clarithromycin $500 \mathrm{mg}$ b.i.d and amoxicillin 1 gr b.i.d) for Helicobacter pylori treatment. In the beginning, eradication rates were above $90 \%$ in many countries; however, current studies have demonstrated a prominent decrease in successful treatment rates, even down to $60 \%$. This unfavorable reduction stimulated searches for new treatment protocols. Treatment protocols differ according to country, prevalence, cost-effectiveness, antibiotic resistance, CYP2C19 polymorphism and eradication rates. Thus, each country/region needs to revise its own therapeutic results and the efficacy of various eradication regimens in the treatment of Helicobacter pylori. This report aims to review the current status of Helicobacter pylori treatment in Turkey and to provide recommendations for rational therapeutic considerations for the eradication of the bacterium.
\end{abstract}

Keywords: Eradication; Helicobacter pylori; proton pump inhibitors; Turkey.

Cite this article as: Kaplan M, Tanoglu A, Duzenli T, Tozun AN. Helicobacter pylori treatment in Turkey: Current status and rational treatment options. North Clin Istanb 2020;7(1):87-94.

$H$ elicobacter pylori $(\mathrm{Hp})$ is a frequently encountered gram-negative pathogenic bacterium that affects almost half of the world population [1]. This worldwide common agent discovered by J.R. Warren and B. Marshall in 1982 has been linked to gastric cancer and many other malignant and non-malignant diseases [2, 3]. $\mathrm{Hp}$ prevalence is $10-50 \%$ in developed countries and $80 \%$ in developing countries, the annual incidence being $1 \%$ and $5-10 \%$, respectively. The epidemiology of $\mathrm{Hp}$ varies widely according to age, socioeconomic status and geographic area $[1,4]$. The age-related prevalence in developing countries ranges between $5 \%$ for the $0-5$ age group and up to $60 \%$ for the $5-17$ age group, yet $\mathrm{Hp}$ infection is markedly more prevalent at younger ages in developing countries than in developed countries [2-4].
This high prevalence of $\mathrm{Hp}$ and the burden of associated diseases has made its eradication a challenging issue. Since conventional triple therapy used for Hp eradication has shown decreasing success, other options have come into question. In recent years, treatment regimens have included sequential therapies, concomitant therapies, and hybrid therapies used in various combinations $[2,4]$. The main point is that eradication rates of $\mathrm{Hp}$ differ between countries, particularly due to differences in antibiotic resistance [4-6]. Thus, each country/region needs to revise its own therapeutic results and the efficacy of various eradication regimens in the treatment of $\mathrm{Hp}$. This report aims to review the current status of $\mathrm{Hp}$ treatment in Turkey and to provide recommendations for rational therapeutic considerations for its eradication.

Received: Februay 02, 2019 Accepted: May 14, 2019 Online: July 11, 2019

Correspondence: Dr. Mustafa KAPLAN. Sultan Abdulhamid Han Egitim ve Arastirma Hastanesi, Gastroenteroloji Klinigi, Tibbiye Caddesi, Uskudar, Istanbul, Turkey. 


\section{Epidemiology}

According to the TURHEP study, the prevalence of $\mathrm{Hp}$ in Turkey is $82.5 \%$ [2]. Bor et al. demonstrated that $\mathrm{Hp}$ prevalence is inversely proportional to reflux prevalence [7]. H. pylori is most prevalent in the Southeastern Anatolia region at a rate of $88.7 \%$, where the reflux prevalence is around $17 \%$. However, in the Marmara region, the Hp prevalence is low at $71.8 \%$, while the reflux prevalence is $27.3 \%$ [7]. In a multi-centered study consisting of biopsies taken during routine endoscopy procedures, the prevalence of $\mathrm{Hp}$ was $65 \%$ [8]. In another study from the Erzurum region, it was reported to be $71 \%$ [9].

In addition to its high prevalence in children from families with low socioeconomic status, other risk factors for Hp are unclean water and food, being raised in a crowded family with an infected mother or father, and contact with infected devices or stomach contents [10-12]. Chronic infection usually takes place during infancy through intra-familial transmission from mother to baby by direct contact or contamination of saliva or feces transmitted by food, water, or medical devices [1011]. Also, endogenous infection by the the colonization of the teeth is important. Anand et al. showed that dental stones and plaques are an important source of re-infection after Hp treatment. Hence, it should not be forgotten that these plaques constitute an important target for the eradication of $\mathrm{Hp}[13]$.

The prevalence of $\mathrm{Hp}$ infection in the adult population does not decrease with the improvement of sanitation conditions in the country, although childhood $\mathrm{Hp}$ diminishes by resolving the sanitation problems and development of healthier living conditions. A reduction in the prevalence of adults can be achieved by effective eradication of $\mathrm{Hp}$ [13-15]. For rapidly developed economies, such as Japan, the prevalence of $\mathrm{Hp}$ is expected to decline in all age groups, even to become a rare disease in the future [16]. Eradication is successful if Hp cannot be shown at least 4 weeks - or 3-6 months, according to some experts - after the end of the treatment $[10,11,13]$. Infection by another Hp strain after absolute eradication is true re-infection, which is rare in adults. Recurrence of $\mathrm{Hp}$ at six months is $1.7 \%$ when the ER exceeds $80 \%$ and $20 \%$ if the ER is $<80 \%$ [16].

After acute infection in childhood, the disease may progress to gastric and duodenal ulcers, MALT lymphoma, atrophic gastritis, dysplasia, or carcinoma in adulthood or may continue to be asymptomatic [14-16]. In accordance with this, The Kyoto global consensus re- port by the Japanese Society of Gastroenterology recommends treating all patients with Hp gastritis [15].

\section{Diagnosis}

Hp diagnostic tests consist of invasive and non-invasive tests. The most common non-invasive tests are serology, urea breath test and stool antigen tests, whereas invasive tests are the rapid urease test, histopathology, culture and PCR $[1,2,4]$. After an effective eradication treatment, control using the urea breath test is commonly used following discontinuation of antibiotics for one month and proton pump inhibitors for 7-14 days. If the urea breath test is not available, a stool antigen test is appropriate $[1,4]$.

\section{Treatment}

After FDA approval in 1995, many countries have used standard triple therapy (PPI b.i.d, clarithromycin $500 \mathrm{mg}$ tb b.i.d and amoxicillin $1 \mathrm{gr}$ tb b.i.d) for Hp treatment [5]. Although treatment success rates at the beginning were above $90 \%$ in many countries, studies demonstrated a gradual decline in the eradication rates in the subsequent years, even down to $60 \%$ [14-15]. This reduction stimulated searches for new treatment protocols. In Turkey, this rate was found to have decreased to $55.7 \%[9,17]$.

The eradication rate for sequential treatment (PPI 40 $\mathrm{mg}$ b.i.d and amoxicillin $1 \mathrm{gr}$ b.i.d for the first five days and PPI b.i.d, clarithromycin $500 \mathrm{mg}$ b.i.d and metronidazole $500 \mathrm{mg}$ t.i.d for the next five days) was higher at the beginning but decreased to $80 \%$ in the following years whereas concomitant therapy (PPI $40 \mathrm{mg}$ b.i.d and amoxicillin 1 gr b.i.d, clarithromycin $500 \mathrm{mg}$ b.i.d and metronidazole $500 \mathrm{mg}$ t.i.d) showed a success greater than $90 \%$ in the first years, but decreased to $80 \%$ subsequently $[5,8]$. The rates of eradication for levofloxacin-based treatments (PPI $40 \mathrm{mg}$ b.i.d, levofloxacin 500 mg b.i.d, amoxicillin $1 \mathrm{gr}$ b.i.d) used as first-line treatment were around $80-85 \%[8,17]$. In the literature, it has been proposed that clarithromycin resistance rates have now reached $\sim 40 \%$ in Turkey. Moreover, increasing levofloxacin resistance is another important concern since the restriction of macrolides use. And of course, increased prevalence of primary levolloxacin resistance may easily and negatively affect the efficacy of levofloxacin-based regimens [18].

The indications for $\mathrm{Hp}$ treatment and the drugs which are used are shown in Table 1 and Table 2, respectively. European Medicines Agency recommendation for an- 
TABLE 1. Indications for $H$. Pylori treatment

Conditions requiring treatment:

1. Duodenal or gastric ulcer (without activity or complication)

2. MALT-lymphoma (gastric)

3. Atrophic gastritis

4. Story of previous gastric surgery

5. Gastric cancer in first-degree relatives

6. If the patient him/herself wants Hp eradication therapy

Conditions where treatment can be recommended:

1. Dyspepsia patients

2. Gastroesophageal reflux disease patients

3. NSAID users

4. Idiopathic thrombocytopenia

5. Unexplained anemia of iron deficiency

6. Other controversial extragastric conditions (such as IHD, DM)

TABLE2. Drugs which are used in Hp treatment

\section{Antibiotics}

Amoxicillin (A) 2X1000 mg

Clarithromycin (K) 2X500 mg

Metranidazole (M) $3 \times 500 \mathrm{mg}$

Tetracycline (T) 4X500 mg

Levofloxacin (L) $1 \times 500 \mathrm{mg}$

Tinidazole (Ti)

Doxycycline (D)

Furazolidone (F)

Rifabutin (R)

PPIs

Omeprazole (O)

Lansaprazole $(L)$

Pantoprazole (P)

Esomeprazole (E)

Rabeprazole ( $R$ )

Bismuth salts (4X1)

Ranitidine bismuth citrate

Colloid bismuth citrate

Bismuth subsalicylate

PPIs: Proton pump inhibitors.

tibiotic sensitivity and resistance rates in Hp treatment are displayed in Table 3.

Current drugs used in the treatment of Hp are rather limited. Several combinations of regimens have been
TABLE 3. European Medicines Agency recommendation for antibiotic sensitivity and $\mathrm{Hp}$ resistance rates (\%)

European Medicines Agency recommendation for antibiotic sensitivity:

$\begin{array}{lc}\text { Generally sensitive } & <10 \\ \text { Rarely sensitive } & 10-50 \\ \text { Usually resistant } & >50\end{array}$

Clarithromycin is important for areas with the resistance of less than 20\%; primary treatment can still be applied as a classical

3-drug therapy.

Resistance rates in $\mathrm{Hp}$ treatment:

Clarithromycin

Levofloxacin

Approximately 40-50

Metronidazole

41

Amoxycillin

$50-76$

$0.5-1.1$

used and recently updated. Furthermore, the emergence of antibiotic-resistant bacteria in countries where antimicrobials are extensively used and the paucity of centres providing culture and antibiogram facilities for $\mathrm{Hp}$ makes the management of this fastidious bacterium even more challenging. The duration of treatment should be at least 14 days. PPIs should be taken half an hour before meals and all other medications after meals. Bismuth salts, tetracycline and metronidazole are not affected by $\mathrm{pH}$ changes. Gastric $\mathrm{pH}$ affects amoxicillin and clarithromycin [1].

\section{H. Pylori Treatment in Turkey}

Eradication rates of bismuth-containing quadruple regimen in Turkey vary between $77 \%$ and $96.4 \%$, and sequential treatment varies between $39 \%$ and $82 \%$ [1, 5]. For bismuth-containing sequential treatments or levofloxacin containing treatments, the ER range from $82 \%$ to $95 \%[5,8]$. With concomitant treatment, $75 \%$ and $90 \%$ ER were reported and eradication with hybrid treatment is around $83 \%$. In levofloxacin-based treatment protocols (PPI $40 \mathrm{mg}$ b.i.d., levofloxacin $500 \mathrm{mg}$ b.i.d and amoxicillin $1 \mathrm{gr}$ b.i.d), ER range from $56 \%$ to $84 \%[8,17,19]$.

In their study Erdoğan et al. demonstrated eradication rates of $52.6 \%$ to $72.4 \%$ with classical triple treatment, concomitant treatment and bismuth-containing quadruple protocols. Overall, eradication rates with these treatment protocols are low in our country, Turkey [20]. 
One of the important issues in designing the treatment protocol is the drug interactions, which are too often overlooked when combining antibiotics, and as a result, random protocols might be generated. When antibiotics are combined, quinolones, nitroimidazoles and rifampicin should not be in the same group. Otherwise, they will all affect bacterial RNA/DNA. Likewise, tetracyclines and macrolides should not be combined since they both disrupt bacterial ribosomal function. Tetracycline antagonizes the antibacterial effects of penicillin $[14,16,17]$. Calhan et al, used levofloxacin based sequential and bismuth-containing quadruple therapy protocols and reported eradication rates of $85.7 \%$ and $93.1 \%$, and there was no statistically significant difference between the two groups. Thus, levofloxacin-based therapies are recommended for second-line treatment in Turkey [17].

The sequential HP eradication protocol consists of: PPI + amoxicillin for the first seven days and PPI + metronidazole + tetracycline for the second seven days. The ER in patients with clarithromycin resistance was $90 \%$ in Italy and $88 \%$ in Turkey $[1,5,8]$. The eradication rate of 300 patients treated for 10 days with levolloxacinbased protocols was 77\% [19]. Levofloxacin can be used as the second choice with penicillin allergy [19]. Aydin et al. used rabeprazole + amoxicillin for seven days and rabeprazole + levofloxacin + metronidazole for the next seven days and indicated an eradication rate of $80 \%$ [21]. In 2006, Gisbert reported a $66 \%$ eradication rate with levofloxacin [22]. In a multicentre study by Basyigit et al., they applied hybrid treatment protocols based on levofloxacin and the eradication rate was 79.3\%. Eventually, they did not suggest this treatment regimen because of ineffectual-cost effectiveness [23].

The last option is rifabutin-based treatments, but they cannot be recommended in our country. Antibacterial activity is not affected by gastric acid in rifampicin containing therapies. Though rifabutin resistant $\mathrm{Hp}$ strains have not been isolated, it can only be applied in patients who have received twice but failed Hp treatment. The eradication rate with PPI + amoxicillin + rifabutin for 14 days is $79 \%$. Reported side effects are serious neutropenia and thrombocytopenia $[1,5,8]$.

Recommendations of classical treatment protocols in case of high clarithromycin resistant patients are exhibited in Table 4. Studies about new and experimental approaches for the treatment of HP is still going on. However, no worldwide accepted eradication option has been emerged yet (see some examples in Table 5).

TABLE 4. Recommendations of classical treatment protocols in case of high clarithromycin resistant patients

First-line treatment

Second-line treatment

Third-line treatment/ rescue treatments Penicillin allergy

*Tetracycline resistance is rare, metranidazole resistance is widespread but can be overcome by prolonging the treatment duration.

TABLE 5. New and experimental approaches for the treatment of HP

Liposomal Linoleic Acid (Lipo LLA)

Synthetic antimicrobial peptide; Pexiganan

Probiotics

Phytomedicine (thyme oil, cinnamon, clove oil)

$\mathrm{N}$-Acetyl cysteine, capsaicin, red ginseng

Green tea, red wine

Photodynamic therapy

Vaccination (preventive vaccination against urease $\rightarrow$ efficacy

$71.8 \%$ ) (China)

Re-immunization of suppressed T cell response (Germany)

\section{Role of PPI's in Hp Eradication Therapy}

Most of the PPIs used in Turkey are metabolized via the CYP2C19 enzyme of the cytochrome P450 system (omeprazole, lansoprazole and pantoprazole prominently, and rabeprazole and esomeprazole to a lesser degree) [11]. The important point here is that the enzyme does not metabolize these drugs at the same rates for everyone because of regional differences. Individuals are divided into three groups according to their metabolism:

\section{Fast metabolizers}

\section{Moderate metabolizers}

3. Slow metabolizers

In trials of triple therapy containing PPIs, the CYP2C19 polymorphism appears to be $20-25 \%$ effective in Hp eradication. In 2003, Miehlke et al. studied Omeprazole 4 x $40 \mathrm{mg}+$ Amoxicillin 4 x $750 \mathrm{mg}$ for 14 days and the rate of eradication was reported as $76 \%$ [24]. 
TABLE 6. Hp eradication rates in different CYP2C19 genotypes

\begin{tabular}{lcc} 
& & Eradication rate \\
Treatment & Fast & $\begin{array}{c}\text { Moderate } \\
\text { metabolizing (\%) }\end{array}$ \\
\cline { 2 - 3 } metabolizing (\%) & $\begin{array}{c}\text { Slow } \\
\text { metabolizing (\%) }\end{array}$ & 64 \\
\hline Dual therapy; PPI + Amoxicillin & 50 & 97 \\
Triple therapy; PPI + Amoxicillin + Clarithromycin & 76 & 89 \\
Quadruple therapy; PPI + Amoxicillin + Clarithromycin + Metronidazole & 80 & 90
\end{tabular}

In a study by Furuta et al. investigating the CYP2C19 polymorphism, they used amoxicillin 1 gr $2 x 1$ with omeprazole $4 \times 1$ in all groups (rapid, moderate and slow metabolizing) for two weeks [25]. Eradication rates were $28.6 \%$ in the fast metabolizing group and $60 \%$ in the moderate group, while in the slow metabolizing group, it was $100 \%$. This study demonstrates the importance of CYP2C19 polymorphism in eradication therapies [25]. Intragastric $\mathrm{pH}$ after PPI treatment was analyzed according to the CYP2C19 gene polymorphism. The fast metabolizing group had a $\mathrm{pH}$ of $3-4$. In the moderate group, itwas between 4 and 5 and the $\mathrm{pH}$ in the slow metabolizing group was over 5.4 . Hp eradication rate in different CYP2C19 genotypes is shown in Table 6.

Ormeci et al. investigated the effects of high-dose proton pump inhibitors on the eradication of the rapid metabolizing group. They added different PPIs (pantoprazole and rabeprazole) to the classical triple clarithromycin-based treatment. They found that ER exceeded $80 \%$ with high-dose PPI [26]. Moreover, the ER for fast, moderate and slow metabolisers in our country was $78 \%, 19.5 \%$ and $2.5 \%$, respectively. Studies of the CYP2C19 polymorphism in Turkey pointed out that the percentage of 'poor' metabolizers was $1-5 \%$ and 'homozygous extensive' metabolizers were $75-84 \%$ [26]. Thus, proton pump inhibitors were recommended to be prescribed at higher doses for Hp treatment in our country compared to the rest of the world. PPIs should also be administered at certain intervals - usually as $4 \times 1$. This approach can also facilitate control of night acidity. Thus, "nocturnal acid breakthrough" could be avoided.

The duration of treatment should not be fewer than 14 days unless 10 days of treatment is proven to be sufficient. It is also suggested that esomeprazole and rabeprazole should be the preferred PPIs in Europe and North America due to the high rate of rapid metabolizers [26, 27].
Celebi et al. administered proton pump inhibitors to different groups and examined gastric $\mathrm{pH}$ on day 1 and day 5 [28]. On the first day, PPIs had increased the gastric $\mathrm{pH}$ to above 4 : with pantoprazol $35 \%$, esomeprazole $67 \%$, lansoprazole $68 \%$ and rabeprazole $60 \%$, respectively. And on the fifth day, the results were pantoprazole $59 \%$, esomeprazole $67 \%$, lansoprazole $68 \%$ and rabeprazole $60 \%$. Esomeprazole was the fastest proton pump inhibitor that increased gastric $\mathrm{pH}$ above 4 [28].

\section{Other Different Treatment Modalities Regarding} Eradication

In the Maastricht V/Florence consensus report, triple or quadruple treatment protocols containing fluoroquinolone are recommended as second-line when eradication cannot be achieved with bismuth quadruple therapy. If eradication cannot be achieved with second-line treatment, culture and antibiotics are recommended in the third step. In the case of fluoroquinolone resistance, different antibiotics, or rifabutin-containing treatment protocols may be used [18]. The Toronto Consensus report also recommends a quadruple therapy protocol containing bismuth as first-line treatment [29]. Treatment success has gradually decreased over the years in bismuth-free regimens, yet there was no reduction in bismuth-containing regimens [29].

In the last 10 years, the success rate of triple therapy has fallen below $80 \%(50-79 \%)$ due to resistance to metronidazole and clarithromycin $[5,8]$. Thus, triple treatment is recommended as the first option only in communities with resistance lower than $15-20 \%$ for clarithromycin and $40 \%$ for metronidazole [26, 28]. Bismuth + PPI + two antibiotics are recommended in populations with high resistance, and if bismuth is not possible, quadruple treatments, such as PPI + three antibiotics, can be used. 
TABLE7. Recommendations for HP eradication

1) Bismuth quadruple therapy (PPI + Bismuth + Two antibiotics)*

2) Bismuth-out quadruple therapy (PPI + Three antibiotics)

3) High dose PPI (4X1) + Amoxicillin 500 mg (4x1) + Tetracycline 500 mg (3 x 1) + Metronidazole $500 \mathrm{mg}(3 \times 1)$

First-line therapy: Bismuth containing quadruple therapy

Esomeprazole $40 \mathrm{mg}$ or rabeprazole $20 \mathrm{mg}$ tb $3 \times 1$

Colloidal bismuth subcitrate $300 \mathrm{mg}$ tb $4 \times 1$

Tetracycline $500 \mathrm{mg}$ tb $4 \times 1$

Metronidazole $500 \mathrm{mg}$ tb $3 \times 1$

Second-line therapy: Concomitant (without bismuth) quadruple therapy: Esomeprazole $40 \mathrm{mg}$ or rabeprazole $20 \mathrm{mg}$ tb $3 \times 1$ Amoxicillin $750 \mathrm{mg}$ tb $3 \times 1$

Metronidazole $500 \mathrm{mg}$ tb $3 \times 1$

Clarithromycin $500 \mathrm{mg}$ tb $2 \times 1$

Third-line therapy

Fourth-line therapy
Levofloxacin Bismuth containing quadruple therapy: Esomeprazole $40 \mathrm{mg}$ or rabeprazole $20 \mathrm{mg}$ tb $3 \times 1$ Colloidal bismuth subcitrate $300 \mathrm{mg}$ tb $4 \times 1$ Amoxicillin $750 \mathrm{mg}$ tb $3 \times 1$ Levofloxacin $500 \mathrm{mg}$ tb $2 \times 1$

Culture + Treatment should be arranged according to antibiogram result
OR Sequential treatment without bismuth

7 days:

Esomeprazole $40 \mathrm{mg}$ or rabeprazole $20 \mathrm{mg}$ tb $3 \times 1$ Amoxicillin $750 \mathrm{mg}$ tb $3 \times 1$,

7 days;

Esomeprazole $40 \mathrm{mg}$ or rabeprazole $20 \mathrm{mg}$ tb $3 \times 1$ Tetracycline $500 \mathrm{mg}$ tb $4 \times 1$

Metronidazole $500 \mathrm{mg}$ tb $3 \times 1$

\section{OR Hybrid therapy:}

7 days;

Esomeprazole $40 \mathrm{mg}$ or rabeprazole $20 \mathrm{mg}$ tb $3 \times 1$ Amoxicillin $750 \mathrm{mg}$ tb $3 \times 1$

7 days;

Esomeprazole $40 \mathrm{mg}$ or rabeprazole $20 \mathrm{mg}$ tb $3 \times 1$ Amoxicillin $750 \mathrm{mg}$ tb $3 \times 1$

Clarithromycin $500 \mathrm{mg}$ tb $2 \times 1$

Metronidazole $500 \mathrm{mg}$ tb $3 \times 1$

OR Sequential treatment with levofloxacin: 7 days;

Esomeprazole $40 \mathrm{mg}$ or rabeprazole $20 \mathrm{mg}$ tb $3 \times 1$ Amoxicillin $750 \mathrm{mg}$ tb $3 \times 1$

7 days;

Esomeprazole $40 \mathrm{mg}$ or rabeprazole $20 \mathrm{mg}$ tb $3 \times 1$ Amoxicillin $750 \mathrm{mg}$ tb $3 \times 1$

Levofloxacin $500 \mathrm{mg}$ tb $2 \times 1$

OR 14 days;

Esomeprazole $40 \mathrm{mg}$ or rabeprazole $20 \mathrm{mg}$ tb $3 \times 1$ Amoxicillin $750 \mathrm{mg}$ tb $3 \times 1$

Rifabutin $150 \mathrm{mg}$ tb $2 \times 1$

OR 7 days;

Esomeprazole $40 \mathrm{mg}$ or rabeprazole $20 \mathrm{mg}$ tb $3 \times 1$ Colloidal bismuth subcitrate $300 \mathrm{mg}$ tb $4 \times 1$ Tetracycline $500 \mathrm{mg}$ tb $4 \times 1$

Furazolidone $200 \mathrm{mg}$ tb $2 \times 1$
Sezikli M. et al. used vitamin C and E supplementation in addition to standard triple therapy and the result was an increase in HP eradication from $60 \%$ to $91.25 \%$ [30]. A similar study was performed by Demirci $H$. et al. and they found no difference in eradication rates (76\%) [31].

The effects of smoking on treatment success are conflicting in the literature, but a recent large study has sug- gested that smoking increases the likelihood of unsuccessful first-line treatment for $H$. pylori infection [32].

Cekin et al. added probiotics to the standard triple treatment and they found no difference in eradication rates. There were also fewer side effects in the standard treatment group [33]. Probiotics are proposed to reduce antibiotic side effects with the current treatment proto- 
cols. In cases of penicillin allergy, bismuth-containing quadruple therapy protocols may be applied [33]. Recommendations for HP eradication are shown in Table 7.

\section{Conclusion}

There are many studies about treatment options for $\mathrm{Hp}$ in the literature. Treatment protocols vary according to country, prevalence, cost-effectiveness, antibiotic resistance, CYP2C19 polymorphism and eradication rates. As a high prevalence country, we recommend bismuth-containing quadruple therapy or sequential therapies (without bismuth) for the first-line treatment $[16,34,35]$. For the second line, concomitant (without bismuth) quadruple therapy or hybrid therapy, and for the third line, levofloxacine containing regimens can be administered [16, $34,35]$. As the last step, treatment should be arranged according to antibiogram results. Above all, the importance of patient compliance must be remembered for successful treatment. For the future, an increase in antibiotic resistance looks inevitable; however, effective treatment protocols can still be delivered by combining several agents.

Conflict of Interest: No conflict of interest was declared by the authors.

Financial Disclosure: The authors declared that this study has received no financial support.

Authorship Contributions: Concept - MK, AT, TD, ANT; Design - MK, AT, TD; Supervision - MK, AT, TD, ANT; Materials - MK, AT, TD; Data collection and/or processing - MK, AT, TD; Analysis and/ or interpretation - MK, AT, TD, ANT; Writing - MK, AT, TD; Critical review - MK, AT, TD, ANT.

\section{REFERENCES}

1. Hunt RH, Xiao SD, Megraud F, Leon-Barua R, Bazzoli F, van der Merwe $\mathrm{S}$, et al. Helicobacter pylori in developing countries. World Gastroenterology Organisation Global Guideline. J Gastrointestin Liver Dis 2011;20:299-304.

2. Ozaydin N, Turkyilmaz SA, Cali S. Prevalence and risk factors of Helicobacter pylori in Turkey: a nationally-representative, cross-sectional, screening with the ${ }^{13} \mathrm{C}$-Urea breath test. BMC Public Health 2013;13:1215. [CrossRef]

3. Warren JR, Marshall B. Unidentified curved bacilli on gastric epithelium in active chronic gastritis. Lancet 1983;1:1273-5. [CrossRef]

4. Peleteiro B, Bastos A, Ferro A, Lunet N. Prevalence of Helicobacter pylori infection worldwide: a systematic review of studies with national coverage. Dig Dis Sci 2014;59:1698-709. [CrossRef]

5. Jung YS, Park CH, Park JH, Nam E, Lee HL. Efficacy of Helicobacter pylori eradication therapies in Korea: A systematic review and network meta-analysis. Helicobacter 2017;22. [CrossRef]

6. Losurdo G, Leandro G, Principi M, Giorgio F, Montenegro L, Sorrentino $C$, et al. Sequential vs. prolonged 14-day triple therapy for
Helicobacter pylori eradication: the meta-analysis may be influenced by 'geographical weighting'. Int J Clin Pract 2015;69:1112-20. [CrossRef]

7. Bor S, Kitapcioglu G, Kasap E. Prevalence of gastroesophageal reflux disease in a country with a high occurrence of Helicobacter pylori. World J Gastroenterol 2017;23:525-32. [CrossRef]

8. Bayındır Bilman F, Özdemir M, Baysal B, Güzel Kurtoğlu M. Prevalence of $H$. pylori in gastric biopsy specimen in the southeastern region of Turkey. J Infect Dev Ctries 2016;10:1177-82.

9. Uyanikoglu A, Coskun M, Binici DN, Kibar YI, Tay A, Ozturk Y. Evaluation of gastroscopic and pathologic results in Erzurum region. Türkiye Klinikleri J Gastroenterohepatol 2011;18:70-4.

10. Leja M, Axon A, Brenner H. Epidemiology of Helicobacter pylori infection. Helicobacter 2016;21 Suppl 1:3-7. [CrossRef]

11. Xin Y, Manson J, Govan L, Harbour R, Bennison J, Watson E, et al. Pharmacological regimens for eradication of Helicobacter pylori: an overview of systematic reviews and network meta-analysis. BMC Gastroenterol 2016;16:80. [CrossRef]

12. Matsuhisa T. The trend of Helicobacter pylori infection rate: time, region, race and strain. Helicobacter Res 2015;19:469-80.

13. Anand PS, Nandakumar K, Shenoy KT. Are dental plaque, poor oral hygiene, and periodontal disease associated with Helicobacter pylori infection? J Periodontol 2006;77:692-8. [CrossRef]

14. Kim SY, Choi DJ, Chung JW. Antibiotic treatment for Helicobacter pylori: Is the end coming? World J Gastrointest Pharmacol Ther 2015;6:183-98. [CrossRef]

15. Sugano K, Tack J, Kuipers EJ, Graham DY, El-Omar EM, Miura S, et al. Kyoto global consensus report on Helicobacter pylori gastritis. Gut 2015;64:1353-67. [CrossRef]

16. Inoue M. Changing epidemiology of Helicobacter pylori in Japan. Gastric Cancer 2017;20:3-7. [CrossRef]

17. Calhan T, Kahraman R, Sahin A, Senates E, Doganay HL, Kanat E, et al. Efficacy of two levofloxacin-containing second-line therapies for Helicobacter pylori: a pilot study. Helicobacter 2013;18:378-83. [CrossRef]

18. Malfertheiner P, Megraud F, O’Morain CA, Gisbert JP, Kuipers EJ, Axon AT, et al; European Helicobacter and Microbiota Study Group and Consensus panel. Management of Helicobacter pylori infection-the Maastricht V/Florence Consensus Report. Gut 2017;66:6-30. [CrossRef]

19. Gisbert JP, Luna M, Gómez B, Herrerías JM, Monés J, Castro-Fernán$\operatorname{dez} \mathrm{M}$, et al. Recurrence of Helicobacter pylori infection after several eradication therapies: long-term follow-up of 1000 patients. Aliment Pharmacol Ther 2006;23:713-9. [CrossRef]

20. Erdoğan FA, Abacı K, Serin E, Özer B, İçer MO. Are first-line Helicobacter pylori eradication therapies alarming? Akademik Gastroenteroloji Dergisi 2009;8:59-62.

21. Aydın Y, Nazlıgül Y, Yeniova AÖ, Kefeli A, Şimşek G, Saçıkara M, et al. The efficacy of levofloxacin based triple therapy for first-line Helicobacter pylori eradication Dicle Med J 2011;38:197-201. [CrossRef]

22. Gisbert JP, Morena F. Systematic review and meta-analysis: levofloxacin-based rescue regimens after Helicobacter pylori treatment failure. Aliment Pharmacol Ther 2006;23:35-44. [CrossRef]

23. Başyiğit S, Kefeli A, Sapmaz F, Doğan Ö, Yeniova AÖ. Evaluating the efficacy and safety of levofloxacin containing hybrid treatment protocol in the first-line therapy of Helicobacter pylori eradication. Akademik Gastroenteroloji Dergisi 2016;15:97-101.

24. Miehlke S, Hansky K, Schneider-Brachert W, Kirsch C, Morgner A, Madisch A, et al. Randomized trial of rifabutin-based triple therapy and high-dose dual therapy for rescue treatment of Helicobacter pylori resistant to both metronidazole and clarithromycin. Aliment Pharmacol Ther 2006;24:395-403. [CrossRef] 
25. Furuta T, Ohashi K, Kamata T, Takashima M, Kosuge K, Kawasaki $\mathrm{T}$, et al. Effect of genetic differences in omeprazole metabolism on cure rates for Helicobacter pylori infection and peptic ulcer. Ann Intern Med 1998;129:1027-30. [CrossRef]

26. Ormeci A, Emrence Z, Baran B, Soyer OM, Gokturk S, Evirgen S, et al. Can Helicobacter pylori be eradicated with high-dose proton pump inhibitor in extensive metabolizers with the CYP2C19 genotypic polymorphism? Eur Rev Med Pharmacol Sci 2016;20:1795-7.

27. Klotz U. Clinical impact of CYP2C19 polymorphism on the action of proton pump inhibitors: a review of a special problem. Int J Clin Pharmacol Ther 2006;44:297-302. [CrossRef]

28. Çelebi A, Aydın D, Kocaman O, Konduk BT, Şentürk Ö, Hülagü S. Comparison of the effects of esomeprazole $40 \mathrm{mg}$, rabeprazole $20 \mathrm{mg}$, lansoprazole $30 \mathrm{mg}$, and pantoprazole $40 \mathrm{mg}$ on intragastric $\mathrm{pH}$ in extensivemetabolizer patients with gastroesophageal reflux disease. Turk J Gastroenterol 2016;27:408-14. [CrossRef]

29. Fallone CA, Chiba N, van Zanten SV, Fischbach L, Gisbert JP, Hunt $\mathrm{RH}$, et al. The Toronto Consensus for the Treatment of Helicobacter pylori Infection in Adults. Gastroenterology 2016;151:51-69. [CrossRef]

30. Sezikli M, Çetinkaya ZA, Güzelbulut F, Yeşil A, Coşgun S, Kurdaş OÖ. Supplementing vitamins $\mathrm{C}$ and $\mathrm{E}$ to standard triple therapy for the eradication of Helicobacter pylori. J Clin Pharm Ther 2012;37:282-5.

31. Demirci H, Uygun İlikhan S, Öztürk K, Üstündağ Y, Kurt Ö, Bilici M, et al. Influence of vitamin $\mathrm{C}$ and $\mathrm{E}$ supplementation on the eradication rates of triple and quadruple eradication regimens for Helicobacter pylori infection. Turk J Gastroenterol 2015;26:456-60. [CrossRef]

32. Itskoviz D, Boltin D, Leibovitzh H, Tsadok Perets T, Comaneshter D, Cohen A, et al. Smoking increases the likelihood of Helicobacter pylori treatment failure. Dig Liver Dis 2017;49:764-8. [CrossRef]

33. Cekin AH, Şahintürk Y, Akbay Harmandar F, Uyar S, Yolcular BO, Çekin Y. Use of probiotics as an adjuvant to sequential H. pylori eradication therapy: impact on eradication rates, treatment resistance, treatment-related side effects, and patient compliance. Turk J Gastroenterol 2017;28:3-11. [CrossRef]

34. Fu W, Song Z, Zhou L, Xue Y, Ding Y, Suo B, et al. Randomized Clinical Trial: Esomeprazole, Bismuth, Levofloxacin, and Amoxicillin or Cefuroxime as First-Line Eradication Regimens for Helicobacter pylori Infection. Dig Dis Sci 2017;62:1580-9. [CrossRef]

35. Kekilli M, Onal IK, Ocal S, Dogan Z, Tanoglu A. Inefficacy of triple therapy and comparison of two different bismuth-containing quadruple regimens as a firstline treatment option for helicobacter pylori. Saudi J Gastroenterol 2016;22:366-9. [CrossRef] 